\title{
TITULARES DE DEREGHOS MINEROS Y ENERGÍAS RENOVABLES EN GHILE: UN CONFLICTO NO RESUELTO
}

\author{
Agustín Martorell Awad*
}

\begin{abstract}
Resumen
El artículo sostiene que la estructura actual de las concesiones mineras otorgadas por el Estado de Chile afecta el desarrollo de proyectos de energía renovable. Luego se explica cómo este conflicto podría solucionarse utilizando la accomodation doctrine desarrollada en Texas. También se discute cómo esta doctrina podría ser adaptada en el sistema jurídico chileno, y cómo esta solución podría ayudar a mitigar los factores que están deteniendo, demorando o añadiendo costos a los proyectos de energías renovables.
\end{abstract}

Palabras clave: derechos mineros; energías renovables; accomodation doctrine; Texas; Chile.

\section{INTRODUGGIÓN}

En Chile, los desarrolladores de energías renovables están teniendo problemas para llevar a cabo sus proyectos, debido a los conflictos con los propietarios de derechos mineros en la misma área donde planean llevar a cabo un proyecto. El marco regulatorio actual de las concesiones mineras ha generado estos problemas porque permite a los concesionarios mineros detener las obras en la superficie o imponer servidumbres en base a los derechos otorgados a los concesionarios mineros, afectando así el desarrollo de los proyectos. Tal uso de las concesiones mineras se conoce como nuisance value o valor de molestia. ${ }^{1}$ Ha habido ciertos intentos de modificar el sistema de las concesiones mineras, pero a la fecha no han sido exitosos. ${ }^{2}$

En este artículo, argumentaré que la estructura actual de las concesiones mineras otorgadas por el Estado de Chile afecta el desarrollo de proyectos de energía renovable y luego explicaré cómo este conflicto podría solucionarse utilizando la accomodation doctrine desarrollada en Texas. También discutiré cómo esta doctrina podría ser adaptada en el sistema jurídico chileno. Para ello, quisiera describir el marco

* Abogado, Universidad Adolfo Ibáñez (amartorell@prieto.cl). Artículo recibido el 8 de octubre de 2019, aceptado para su publicación el 26 de diciembre de 2019. Traducción al castellano de Fluent Traducciones.

1 Novoa y Bambach (2017), p. 51.

2 El Mercurio S.A.P, Gobierno estudia cambiar mecanismo de concesiones mineras por concentración y especulación de pertenencias <http://diario.elmercurio.com/2014/06/09/economia_y_ negocios/_portada/noticias/6566EF72-2DBB-4B69-BF17-77A651A7BD32.htm?id=\{6566EF722DBB-4B69-BF17-77A651A7BD32\}>. 
regulatorio actual de las concesiones mineras en Chile. Luego explicaré cómo dicho marco está siendo utilizado para detener los proyectos o para incrementar los costos de los proyectos de energías renovables. Después, analizaré cómo el conflicto entre los dueños de la tierra y los titulares de derechos mineros han sido tratados en otras jurisdicciones con el fin de proponer una solución alternativa. En particular, analizaré las soluciones que ha dado la accomodation doctrine en Texas. A continuación, discutiré cómo Chile podría adoptar esta doctrina en su sistema jurídico y cómo esta solución podría ayudar a mitigar los factores que están deteniendo, demorando o añadiendo costos a los proyectos de energías renovables.

\section{MARGO REGULATORIO AGTUAL DE LAS CONGESIONES MINERAS EN GHILE}

\subsection{Marco regulatorio}

El marco regulatorio de industria minera en Chile está contenido y es desarrollado principalmente en tres leyes diferentes. ${ }^{3}$ Esas leyes son la Constitución chilena, la Ley Orgánica Constitucional sobre Concesiones Mineras, y el Código de Minería. ${ }^{4}$ La regulación en diversas leyes e incluir parte de la regulación minera en la Constitución responde a situaciones históricas y políticas. ${ }^{5}$

Este marco contiene los elementos fundamentales de un sistema independiente que podemos llamar legislación minera chilena. ${ }^{6}$ Todo el Sistema está diseñado para proteger la exploración y la explotación minera. ${ }^{7}$ En lo que sigue, describiré solo los aspectos principales del marco regulatorio de la industria minera y me enfocaré solo en las características que resultan relevantes para el alcance de este artículo.

\subsubsection{Constitución}

El artículo 19 número 24 de la Constitución chilena declara que el Estado tiene el dominio absoluto, exclusivo, inalienable e imprescriptible de todas las minas. ${ }^{8}$ Sin embargo, la exploración y explotación de ciertos minerales puede otorgarse a través de concesiones mineras. ${ }^{9}$ En este sentido, aunque el Estado es el dueño de todas las minas, la exploración y explotación se otorgan en concesión a privados, que pueden tener acceso a los minerales obteniendo una concesión otorgada por un tribunal ordinario de justicia y sin participación de un órgano administrativo especial responsable de otorgarlas.

\footnotetext{
3 Vergara Blanco (2014), p. 633.

4 Vergara Blanco (2014), p. 633.

5 Vergara Blanco (2003), p. 23.

6 Vergara Blanco (2014), p. 634.

7 Para más información sobre esta discusión constitucional, ver, entre otros: ZúÑIGA URBINA (2005).

8 Ver Constitución de la República de Chile artículo 19 No 24.

9 Constitución de la República de Chile artículo 19 Nº 24.
} 
La Constitución chilena, además, establece que el Estado es el dueño de todas las minas, teniendo un estatuto diferente a los derechos de dominio sobre la superficie. ${ }^{10}$ Esto significa que en la misma área coexisten dos derechos de propiedad distintos: uno en la superficie y otro sobre las minas. ${ }^{11} \mathrm{El}$ efecto de esta coexistencia es que existen intereses distintos que, en algunos casos, pueden generar conflictos. ${ }^{12}$

Para solucionar los eventuales conflictos debidos a la coexistencia de derechos, la Constitución señala que la superficie está sujeta a las limitaciones y cargas que establezca la ley con el fin de facilitar la exploración y explotación. ${ }^{13}$

En resumen, la Constitución chilena establece un sistema de "dominios separados", lo que significa que distintas partes pueden ser dueñas de la superficie y del mineral. ${ }^{14}$ Además, la Constitución chilena establece la dominancia del titular de los derechos mineros, lo que significa que el dueño de la tierra superficial está obligado a permitir el acceso al titular de derechos mineros, sin perjuicio de los derechos o indemnizaciones a que tenga derecho el primero. ${ }^{15}$

\subsubsection{Ley Orgánica Constitucional sobre Concesiones Mineras}

Las leyes orgánicas constitucionales son un tipo de ley polémico en el sistema chileno. ${ }^{16}$ Hubo razones políticas e históricas que hicieron que Chile adoptara un sistema en el cual algunas leyes requieren de un quórum mayor para ser aprobadas. Ese es el caso de las "Leyes orgánicas constitucionales". Aun cuando estas leyes se encuentran en igual lugar de jerarquía que las leyes simples en el sistema jurídico chileno, las primeras exigen un quórum mayor que estas últimas. La Constitución chilena señala qué materias se someten al procedimiento de las leyes orgánicas constitucionales y, en su momento, el gobierno decidió establecer que algunos aspectos de la industria minera fuesen materias de ley orgánica constitucional. ${ }^{17}$

En términos generales, la Ley Orgánica Constitucional sobre Concesiones Mineras establece los minerales que pueden ser otorgados por concesiones, los tipos de otorgamiento existentes y sus características, los derechos de los concesionarios mineros y las obligaciones asumidas por los titulares bajo estas concesiones. ${ }^{18}$ El Código de minería además regula gran parte de estas materias. La diferencia entre la Ley Orgánica Constitucional sobre Concesiones Mineras y el Código de Minería respecto de su contenido es que el primero establece un marco general, mientras que el segundo contiene una regulación más detallada.

10 Constitución de la República de Chile artículo 19 No 24.

11 Ossa Bulnes (1999), p. 35.

12 Ossa Bulnes (1999), p. 35.

13 Ver Constitución Política de la República de Chile art. 19 No 24.

14 Jones, Welborn y Russell (2013), p. 181.

15 Jones, Welborn y Russell (2013), p. 184.

16 Ver Vergara Blanco (2003).

17 Vergara Blanco (2003), p. 27.

18 Ver Ley Orgánica Constitucional sobre Concesiones Mineras. 
En este punto es relevante destacar la existencia de algunas regulaciones de las concesiones mineras que no pueden ser modificadas por la regla de la mayoría. Por el contrario, ellas requieren de un quórum superior a las leyes simples. Lo anterior hace que cualquier reforma en el contenido de esta ley requiera de, al menos, los votos del $58 \%$ de cada una de las dos Cámaras del Congreso. ${ }^{19}$ Este asunto será discutido más extensamente en este artículo.

\subsubsection{Código de Minería y su Regulación}

El Código de Minería contiene la mayor parte de la regulación sobre concesiones mineras. ${ }^{20}$ Por su parte, el Reglamento del Código de Minería especifica el contenido del Código de Minería. Entregaré una descripción de las características relevantes con base en el objetivo de este artículo, es decir, de los tipos de otorgamiento, las características principales de cada tipo de concesión y algunos elementos de procedimiento.

\section{(a) Tipos de concesiones mineras}

En Chile, existen dos especies de concesiones mineras: concesiones de exploración y las concesiones de explotación. ${ }^{21}$ Cada una otorga distintos tipos de derechos respecto de las fases de un proyecto minero. La concesión de exploración otorga derechos para estudiar y buscar la existencia de minerales en un área determinada. Por otro lado, la concesión de explotación otorga el derecho de obtener y comercializar los minerales que se encuentren en un área determinada. ${ }^{22}$ No es necesario obtener una concesión de exploración previo a obtener una concesión de explotación, aunque el Código de minería establece la preferencia del titular de una concesión de exploración existente para explotar el área cuando solicite una concesión de explotación. En otras palabras, estos títulos no se otorgan de forma consecuencial. ${ }^{23}$ Un tribunal ordinario de justicia es quien otorga ambos tipos de concesión, los que, a su vez, deben pagar una patente para mantener el título. ${ }^{24}$

Ambas concesiones pueden ser revocadas o caducar por ciertas razones determinadas. En términos generales, debe existir una causa para que ellas sean invalidadas, por ejemplo, el incumplimiento de los requisitos técnicos mínimos, o que el titular no pagó la patente anual. ${ }^{25} \mathrm{El}$ lenguaje del Código de Minería para referirse a las causales de extinción es taxativo, señalando que las "únicas" razones establecidas en el código pueden utilizarse para extinguir una concesión minera. ${ }^{26}$

19 Constitución de la República de Chile, artículo 66.

20 Lira Ovalle (1998), p. 49.

21 Ver Código de Minería.

22 Vergara Blanco (1988), p. 250.

23 Ver Código de Minería.

24 Código de Minería.

25 Ossa Bulnes (1999), p. 37.

26 Ver, Código de Minería. 


\section{(b) Características clave de cada tipo de concesión minera ${ }^{27}$ \\ (i) Concesiones de exploración}

Las concesiones de exploración otorgan derecho a buscar minerales en un área determinada. El titular de una concesión de exploración tiene prohibido explotar el área de la concesión. Para que pueda hacerlo, el titular de una concesión de exploración necesita de una concesión de explotación. ${ }^{28}$

Además, las concesiones de exploración duran por un plazo de 2 años y pueden extenderse por dos años más, si el área de la concesión se reduce al menos en un 50\% del área que el titular tenía en la concesión de exploración. ${ }^{29} \mathrm{Al}$ cabo de ese período, el titular puede elegir entre solicitar una concesión de explotación o dejar el área franca, libre para otras concesiones.

\section{(ii) Concesiones de explotación}

Las concesiones de explotación otorgan a su titular el derecho exclusivo de explotar el área dentro de los límites de la concesión. Para ello, el Código de Minería establece varios derechos para acceder a la superficie y cargas al dueño de la tierra superficial con el fin de permitir que el titular de la concesión pueda explotar el área. ${ }^{30}$

Las concesiones mineras son ilimitadas en cuanto a su duración. La principal obligación del titular es pagar la patente anual para mantener el título. De acuerdo con la Constitución chilena, el titular de una concesión minera está obligado a explorar o explotar su concesión. ${ }^{31}$ Sin embargo, no existe un estatuto o regulación que obligue al titular de una concesión minera a explorarla o explotarla en la práctica ${ }^{32}$ De modo que la norma constitucional, a fin de cuentas, no tiene efecto. ${ }^{33}$ La falta de una regulación que asegure el cumplimiento, como se discutirá más adelante, origina uno de los principales problemas que enfrentan los desarrolladores de proyectos de energía renovable.

\subsection{Dominancia de los derechos mineros y derechos relevantes que las concesiones mineras otorgan a sus titulares}

De acuerdo con el sistema descrito, la legislación minera chilena establece un sistema de dominancia de los derechos sobre el mineral, lo que significa que el conflicto de intereses entre el propietario del terreno superficial y el titular de un derecho

27 Para ver una explicación detallada sobre el proceso de constitución de la concesión, ver InsunZA Corvalán (2015), p. 43.

28 Código de Minería, artículo 95.

29 Código de Minería, artículo 112.

30 Código de Minería, sección 120.

31 Constitución de la República de Chile.

32 Vergara Blanco (1989), p. 57.

33 Vergara Blanco (1989), p. 58. 
minero se resuelve ex ante a favor del titular del derecho minero. ${ }^{34}$ En la práctica, esto resulta en otorgar acceso al concesionario minero a su propiedad. ${ }^{35}$ Numerosas leyes denotan la jerarquía del derecho minero por sobre el derecho en la superficie. En esta sección, describiré dos de las consecuencias más importantes de esta dominancia en Chile, que son el derecho a imponer servidumbres sobre la superficie, y la acción del titular minero de inhibir el desarrollo de proyectos de construcción sobre la superficie.

\subsubsection{Imposición de servidumbres}

El Código de Minería permite al concesionario minero imponer servidumbres en la superficie (no necesariamente sobre la misma área de la concesión) para facilitar la exploración y explotación del sitio otorgado en concesión. ${ }^{36}$ La idea de esta servidumbre es proteger el derecho del titular del derecho minero a explorar o explotar el área otorgada. ${ }^{37}$ Antes de utilizar el terreno de la superficie, el titular minero debe acordar con el propietario o inquilino del terreno superficial una indemnización. ${ }^{38}$ Sin embargo, si las partes respectivas no pueden llegar a un acuerdo, el Código de Minería establece un procedimiento sumarísimo para determinar el monto de dicha compensación. ${ }^{39}$

Cabe mencionar que, de acuerdo con el Código de Minería, mientras el juicio para determinar la indemnización esté pendiente, el juez puede autorizar al titular minero a utilizar la superficie si este entrega una garantía. Esta garantía consiste en el pago de una cantidad (determinada por un tribunal) que el peticionario puede pagar para poder acceder de inmediato a la tierra.$^{40}$ Finalmente, es importante mencionar que para que la servidumbre sea oponible a terceros, el beneficiario debe inscribirla. ${ }^{41}$

\subsubsection{Orden judicial de suspender las obras}

La legislación chilena permite al concesionario minero obtener una orden judicial para suspender las obras que efectúe el dueño o el inquilino en la superficie. ${ }^{42}$ La característica principal de esta acción es que, una vez se interpone, el juez debe suspender provisoriamente las obras so pena de una sanción en caso de infringirse la referida orden. ${ }^{43}$ Después de la suspensión de las obras, existe un procedimiento

34 Jones, Welborn y Russell (2013).

35 Wenzel (1993), p. 623.

36 Ver Código de Minería, artículo 120.

37 Obando Camino (2010), p. 270.

38 Código de Minería, artículo 122.

39 Código de Minería, artículo 123.

40 Código de Minería, artículo 125.

41 Código de Minería, artículo 123.

42 Esto no está expresamente contemplado en las leyes chilenas. Sin embargo, la doctrina y la jurisprudencia construyen ese argumento, con referencia al Código de Minería en su artículo 94 sobre las acciones posesorias civiles, en las cuales se ha considerado la orden judicial de suspender obras nuevas.

43 Huerta Molina y Rodríguez Diez (2012), p. 347. 
especial en el cual el tema central a discutir es si se otorga o no la orden judicial. ${ }^{44}$ No se trata de una discusión sobre los derechos de propiedad. ${ }^{45}$ Mientras tanto, el inquilino en la superficie solo puede tomar acciones mínimas como para evitar la destrucción de las obras ejecutadas, pero de ninguna forma puede continuar con la construcción. ${ }^{46}$ Como se explicará a continuación, dada la conformación de la orden judicial, esta se ha utilizado por los titulares de derechos mineros para suspender el desarrollo de proyectos de energía renovable. Aunque en los últimos años se han incluido ciertas instituciones para mitigar este problema, el sentimiento general es que ellas no han sido suficientemente eficientes y no han abordado los problemas estructurales del sistema concesional minero.

Hasta aquí, he descrito el marco regulatorio chileno de la industria minera. En la Parte III, expondré los problemas que genera esta estructura para los proyectos de energía renovable.

\section{ANÁLISIS DE LOS PROBLEMAS GENERADOS POR EL MARGO REGULATORIO DESGRITO}

El marco regulatorio descrito obstaculiza el desarrollo de proyectos de energía renovable en Chile. Al imponer un sistema de derechos sobre las concesiones mineras, los titulares de derechos mineros obligan a quienes desarrollan proyectos energéticos a negociar con ellos, aun cuando el titular de derechos mineros no tenga ni el más mínimo interés en desarrollar un proyecto minero en el área. Este problema del sistema no es nuevo y los tribunales no han fallado este asunto de manera consistente, de modo que el problema persiste. ${ }^{47}$ En esta parte III analizaré las causas y consecuencias que este conflicto puede significar en el mercado energético chileno.

\subsection{Cómo los derechos otorgados en virtud de las concesiones mineras afectan el desarrollo de proyectos de energía}

Como ya se mencionó, el titular de una concesión minera tiene derechos específicos al uso de la superficie a partir de su concesión minera. El objetivo de estos derechos es facilitar la exploración y la explotación de minerales dentro del área de la concesión. ${ }^{48}$ Estos derechos son otorgados por el sistema legal chileno, pudiendo haber en la misma área, como ya se señaló, un propietario del terreno superficial distinto del propietario de los derechos mineros.

Hasta aquí, no se aprecian mayores diferencias con otros sistemas basados en la preferencia de los derechos mineros. En un sistema donde el propietario de la

44 Huerta Molina y Rodríguez Diez (2012), p. 350.

45 Huerta Molina y Rodríguez Diez (2012), p. 350.

46 Huerta Molina y Rodríguez Diez (2012), p. 350.

47 Вамвасн (2003), p. 71.

48 Código de Minería, artículo 120. 
superficie puede dar acceso a la parte que posee derechos mineros, es frecuente que el primero tenga conciencia de ello y usualmente permita el acceso al propietario de derechos mineros para explotar su mineral. ${ }^{49}$

Sin embargo, existen los denominados "especuladores" que utilizan las concesiones mineras con un fin distinto ${ }^{50}$ Estos "especuladores" intentan aprovecharse de los derechos que otorgan estos derechos para obtener compensaciones o pagos por parte de los que desarrollan otro tipo de proyectos. Es decir, los "especuladores" no tienen intención de llevar a cabo un proyecto minero. ${ }^{51}$

El mecanismo que usan los "especuladores" es simple. Solicitan las concesiones mineras en áreas que pueden utilizarse en otro tipo de proyectos, los que probablemente iban a ser desarrollados en la superficie. Luego, cuando quienes quieren comenzar obras en proyectos en la superficie (y recordemos que generalmente el precio de la indemnización que pagan los titulares de derechos mineros es bajo), los "especuladores" aparecen amenazando con usar su derecho minero para imponer servidumbres o suspender las obras, utilizando los mecanismos descritos en la Parte II de este artículo. ${ }^{52}$

Como resultado, quien desarrolle proyectos en la superficie está obligado o a negociar con el titular de la concesión minera aun cuando este último no esté interesado en utilizar el terreno para acceder a los minerales otorgados en la concesión o bien puede solicitar concesiones mineras con el fin de desarrollar proyectos en la superficie. ${ }^{53}$

\subsection{Causas estructurales tras este uso de las concesiones mineras}

El marco regulatorio descrito genera incentivos perversos para el uso de las concesiones mineras. ${ }^{54}$ De hecho, para obtener concesiones mineras no se establecen muchos requerimientos técnicos, como programas de trabajo o análisis de la viabilidad comercial de los proyectos mineros. Lo anterior lleva a un sistema en el cual cualquier persona interesada puede obtener una concesión minera, aunque no tenga interés o conocimientos para llevar a cabo un proyecto minero.

Segundo, al titular de una concesión minera no se le exige explotar su concesión. Aunque existe un mandato constitucional para hacerlo, ${ }^{55}$ no hay regulación que obligue al concesionario en la práctica. De acuerdo con la Constitución chilena, el concesionario debe efectuar las actividades necesarias para satisfacer el interés público, de modo de justificar la validez del permiso otorgado. ${ }^{56}$ Sin embargo, dentro

49 Vergara Blanco (1989).

50 Vergara Blanco (2012), p. 403.

51 Vergara Blanco (2012), p. 404.

52 Vergara Blanco (2012), p. 404.

53 Vergara Blanco (2012), p. 404.

54 Vergara Blanco (2012), p. 404.

55 Constitución de la República de Chile, artículo 19 No 24.

56 Constitución de la República de Chile, artículo 19 No 24. 
del marco regulatorio no existe regulación que permita forzar la ejecución del mandato constitucional. ${ }^{57}$ Lo anterior implica, en la práctica, que se permite solicitar y mantener el dominio sobre concesiones mineras sin que sea necesario invertir en un proyecto minero. Esta es una distorsión de los fines de la concesión minera. ${ }^{58}$

Tercero, dado que los jueces otorgan concesiones mineras contando con una participación mínima de un organismo técnico, ${ }^{59}$ ni los solicitantes ni la autoridad revisan las condiciones operacionales o las capacidades para explotar el área minera. Esto permite que cualquier peticionario solicite concesiones mineras aun en áreas donde la explotación de recursos minerales no es factible. El marco regulatorio actual prioriza los aspectos procesales por sobre la viabilidad de los proyectos. ${ }^{60}$

Finalmente, dado que las concesiones mineras rara vez son revocadas, y las causales existentes para revocarla no se relacionan con el uso práctico de la concesión, las posibilidades de volver a dejar como terreno franco el área cubierta por una concesión minera es escasa. De hecho, hasta 2013, el 41\% del territorio chileno estaba cubierto por concesiones mineras. ${ }^{61}$

Los desarrolladores de proyectos de energía renovable enfrentan este marco regulatorio de las concesiones mineras cada vez que quieren llevar a cabo un proyecto de energía. En la sección siguiente describiré los efectos de los problemas aquí analizados, en relación con los proyectos de energía renovable.

\subsection{Efectos de las cuestiones descritas en proyectos de energía renovable}

Los proyectos de energía renovable requieren amplias extensiones de tierra para ser llevados a cabo. Por ejemplo, un proyecto de parque eólico necesita superficies para las turbinas, caminos, conexiones subterráneas y subestaciones, entre otros. ${ }^{62} \mathrm{El}$ espacio para las turbinas depende de diversos factores y, además, exige considerar áreas libres para evitar obstáculos al uso del recurso. ${ }^{63}$ Los proyectos solares además requieren de una vasta extensión de suelo. Los paneles solares, así como las subestaciones, las redes y otros factores, afectan el área requerida. En Chile, por ejemplo, recientemente se aprobó un proyecto solar que utiliza 1.436 hectáreas para inyectar $210 \mathrm{MW}$ al sistema. ${ }^{64}$

57 Vergara Blanco (1989).

58 Vergara Blanco (2012).

59 Vergara Blanco (1988).

60 Vergara Blanco (1988).

61 Servicio Nacional de Geología y Minería, "Estadísticas Sobre Concesiones Mineras" <http://www.sernageomin.cl/pdf/mineria/estadisticas/estadisticas $\% 20 \mathrm{de} \% 20$ concesiones $\% 20$ mineras/propiedad_minera_2_2013.pdf $>$.

62 Duvivier y Wetsel (2009), p. 9.

63 Duvivier y Wetsel (2009), p. 10.

64 Servicio de Evaluación Ambiental de Antofagasta, "Resolución Exenta 0231/2014". 
En muchos casos, los desarrolladores de proyectos de energía renovable los llevan a cabo sobre una concesión minera de un tercero. En consecuencia, están en riesgo de que sus trabajos se suspendan debido a una orden judicial o se interrumpan por una servidumbre. Esto los obliga a encontrar una solución para mitigar este problema. Además, quienes financian estos proyectos también exigen esta solución.

Para mitigar este riesgo, los desarrolladores de proyectos de energía renovable, generalmente llegan a acuerdo con los concesionarios mineros. La forma de este acuerdo puede variar: pueden ser acuerdos para que adquieran la concesión minera, o servidumbres negativas, en las cuales el concesionario renuncia al uso de la superficie. ${ }^{65}$

Sin embargo, estos acuerdos conllevan varias desventajas. Primero, pueden incrementar los costos de los desarrolladores. ${ }^{66}$ Dado que en la mayor parte de los casos el concesionario cobrará un precio por el acuerdo, el desarrollador considerará, en sus costos, el costo de este acuerdo. La ley no regula el precio de estos contratos y el concesionario no tiene que probar tener ningún interés en el área. Le basta con su status de concesionario.

Segundo, llegar a un acuerdo con un tercero más puede aumentar el retraso en el desarrollo de proyectos de energía. El argumento aquí no es que estos acuerdos sean la única causa para los retrasos de los proyectos, pero sí que pueden influir. Ciertamente, muchos otros factores pueden causar retrasos en los proyectos de energía. ${ }^{67}$ El énfasis debe colocarse en los efectos adversos de los retrasos en los proyectos de energía. En Chile, el impacto en los retrasos para el desarrollo de proyectos de energía puede ser considerable. ${ }^{68}$ Además, estos pueden implicar demoras en que Chile logre sus objetivos de generación de energías renovables. ${ }^{69}$

Tercero, se espera que los desarrolladores, como práctica general, sean capaces de mitigar los mencionados riesgos para que estos puedan obtener financiamiento. ${ }^{70}$ Hasta cierto punto, el desarrollo de proyectos de energía renovable depende, entre otros factores, de que se solucione de manera efectiva este problema. Al final, todo esto resulta en dificultades para los desarrolladores de proyectos de energía renovable para obtener financiamiento de sus proyectos.

65 Gardner, Sewell y Stahl (2010), p. 248. La validez de las servidumbres negativas puede discutirse en el contexto chileno. Pero esto escapa al alcance de este artículo.

66 Vergara Blanco (2012), p. 405.

67 Ver, por ejemplo, Moraga Sariego (2012), p. 376.

68 Ver Agurto et al. (2013), p. 1.

69 De acuerdo con los objetivos en energías renovables para Chile, la participación de energías renovables en el mercado debe ser de $20 \%$ en el año 2025.

70 Olivares, Alfredo et al., "Guía de Gestión. Aspectos Claves en el Desarrollo de Proyectos ERNC" <http://cifes.gob.cl/archivos/guia\%20gestion\%20ernc/Guia\%20de\%20Gestion_\%2001.pdf>. 


\subsection{Falta de una solución consistente}

Como ya se mencionó, este no es un problema reciente. Los desarrolladores lo enfrentan hace años y el sistema jurídico chileno ha adoptado ciertas medidas para prevenir este problema. Sin embargo, ellas no han sido efectivas en la práctica.

\subsubsection{Boleta de garantía para continuar con las obras}

La primera solución que surgió fue una reforma a la Ley General de Servicios Eléctricos incluyendo el artículo 34 bis. De acuerdo con este artículo, si el titular de derechos mineros inicia un proceso para suspender las obras, el desarrollador tiene derecho a pagar una garantía con el fin de poder continuar con las obras. Esta regla tenía un ámbito de aplicación restringido, pues solo era aplicable en (i) proyectos amparados bajo una concesión eléctrica (lo que no es obligatorio en los proyectos de generación eléctrica); (ii) y en los proyectos de energías renovables en islas públicas. En el 2016, el Congreso aprobó una ley para ampliar el ámbito de aplicación, incluyendo los proyectos de energía renovable desarrollados en islas privadas, excluyendo los territorios indígenas. Aunque esta herramienta fue útil, no ha sido muy utilizada en la práctica. Además, desde un punto de vista teórico, no es claro cómo el hecho de que los desarrolladores paguen una garantía ex-ante permite mitigar la acción de los especuladores. Esto podría implicar costos financieros extra a los desarrolladores encareciendo los proyectos.

\subsubsection{Procedimiento de arbitraje}

Otro mecanismo se incluye en el artículo 31 bis de la Ley General de Servicios Eléctricos. La disposición establece un proceso de arbitraje para resolver conflictos entre concesionarios. Específicamente, esta ley permite a cualquier concesionario (eléctrico, minero, geotérmico y otros) forzar el inicio de un procedimiento de arbitraje en caso de problemas con otro concesionario. Aunque la idea era buena, este procedimiento no ayuda mucho para solucionar los problemas del desarrollador de proyectos de energía renovable, puesto que muchos de estos no cuentan con una concesión y el acceso a la tierra es otorgado mediante acuerdos privados.

Estos mecanismos que ayudan a solucionar el problema implican en cualquier caso costos adicionales para el desarrollador y, en la práctica, han sido escasamente utilizados. Como explicaré, los tribunales han ideado otros mecanismos para abordar este problema.

\subsection{La voz de los jueces: Cómo los tribunales abordan la cuestión}

Los tribunales tienen algo que decir. Mediante diversas construcciones, han intentado detener el uso de las concesiones mineras como si fuera un boleto de lotería. A continuación, indico algunas de las principales interpretaciones de los tribunales al respecto en los últimos años.

\subsubsection{Las órdenes judiciales de suspender las obras no proceden bajo cualquier circunstancia}

Como se dijo, los tribunales han intentado limitar los efectos de la suspensión de obras nuevas por parte de los concesionarios mineros. Un mecanismo utilizado para ello es requerir, además de la concesión minera, la existencia de una servidum- 
bre minera para admitir la acción de suspensión de obras nuevas. Este mecanismo ha sido reconocido por la Corte Suprema. ${ }^{71}$ El argumento es: (i) Los concesionarios mineros no tienen un derecho sobre la superficie; (ii) Sin embargo, los concesionarios mineros están facultados para imponer servidumbres mineras; (iii) solo cuando una servidumbre minera ha sido otorgada (judicialmente o por un contrato), el concesionario minero tiene derecho a suspender las obras sobre la superficie; (iv) en consecuencia, si el concesionario minero no prueba la existencia de dicha servidumbre minera, el juez está obligado a denegar la solicitud de suspensión de las obras.

Este argumento suena interesante. Sin embargo, tiene un defecto importante. La mera interposición de la demanda en este proceso obliga a los jueces a ordenar de inmediato la suspensión de las obras. La existencia de la servidumbre será discutida con posterioridad, durante el juicio y la dictación de la sentencia, considerando posibles apelaciones, puede tardar más de un año. En consecuencia, en la práctica el desarrollador de energías renovables tiene que esperar hasta la sentencia definitiva para continuar con las obras, o sea más de un año después. ${ }^{72}$ Agrego, al margen, que construir un proyecto de energía renovable grande en Chile (eólico o solar) puede demorar un año, por lo que el plazo de la suspensión de la obra resulta sustancial en este tipo de proyectos.

Otro enfoque comenzó el año 2019. ${ }^{73}$ Consiste en posponer la decisión sobre la suspensión provisoria, si el juez determina que no hay motivos para determinar el cumplimiento de los requisitos legales. En este caso, el tribunal ha decidido que, puesto que el demandante no ha probado su derecho sobre la superficie, no procede ordenar la suspensión provisoria. ${ }^{74}$

Esta solución parece ser muy buena, puesto que soluciona el mencionado problema de la suspensión provisoria, pero va directamente contra la ley y la intención de la acción de obra nueva. De hecho, el principal propósito de la acción es suspender las obras, con el fin de evitar posibles daños, hasta que la sentencia definitiva solucione el conflicto. ${ }^{75}$ Así y considerando que en el sistema jurídico chileno el precedente judicial no es vinculante hacia el futuro, no es una solución en la cual los desarrolladores puedan confiar.

\subsubsection{Las servidumbres mineras requieren un proyecto minero}

Los tribunales han indicado que, para obtener una servidumbre minera, el solicitante tiene que probar que existe un proyecto minero serio. Normalmente, la seriedad se relaciona con la existencia de permisos ambientales o mineros que, en algunos casos, incluso implican consulta indígena previa.

71 Por ejemplo, Corte Suprema, Rol No 76468-2016, 22 de noviembre de 2016.

72 Nótese que esta solución es previa a la existencia de la garantía analizada. En cualquier caso, la garantía por su parte, tiene sus desventajas.

73 Sotomayor, María José y Chomalí, Juan Luis, "Alentadora interpretación de la suspensión provisional en la denuncia de obra nueva", El Mercurio Legal. Último acceso: 30 de diciembre de 2019.

74 Véase Corte de Apelaciones de Concepción, Rol N 1801-2016.

75 Dossi Osorio (2016), p. 35. 
Aunque parece una solución confiable, tiene un problema importante: es discutible que los tribunales tengan la facultad de denegar una servidumbre minera en base a la seriedad de un proyecto. De hecho, el esquema regulatorio minero no contempla dicha facultad.

\subsection{Esfuerzos para reformar el sistema de concesiones mineras}

El marco regulatorio actual de las concesiones mineras trae problemas a los proyectos de energías renovables en desarrollo. El pragmatismo sugiere modificar el marco regulatorio actual de las concesiones mineras para evitar los problemas señalados y generar un sistema regulatorio con mejores resultados. De hecho, la forma más directa de hacerlo es aprobar una ley para que las regiones que otorguen concesiones mineras tengan que demostrar que existen proyectos mineros que justifiquen el otorgamiento. De lo contrario, los permisos se revocan. Además, la duración de la concesión podría limitarse a un período específico según el tamaño de los proyectos mineros. Sin embargo, esto no es fácil. Reformar el marco regulatorio implica además lidiar con temas constitucionales. Como ejemplo de la dificultad de reformar el sistema actual, mencionemos la reforma a las concesiones mineras que hoy se discute y que busca incrementar los costos de las licencias cuando las concesiones mineras no se usan. El sector privado se ha opuesto, señalando que la reforma causaría incertidumbre para los inversionistas. ${ }^{76}$

\subsubsection{Derechos de propiedad sobre la concesión minera}

Luego de establecer la existencia de los derechos de propiedad sobre las cosas, el Código Civil chileno establece la existencia de un "tipo" de derechos de propiedad sobre intangibles, como los derechos. ${ }^{77}$ A la vez, el artículo 19 número 24 de la Constitución chilena asegura a todas las personas el derecho de propiedad sobre tangibles e intangibles. ${ }^{78}$

Además, existe un procedimiento constitucional especial destinado a recobrar el imperio del derecho y proteger dichos derechos constitucionales. ${ }^{79}$ Por medio de este procedimiento y con base en el amplio alcance que se da en Chile al derecho de propiedad, ${ }^{80}$ la Corte Suprema chilena ha aceptado derechos de propiedad sobre contratos de arriendo, servicios educacionales, concesiones y permisos de edificación, entre otros. ${ }^{81}$

76 "Plan pro Inversión: Gobierno Matiza Cambios y Delinea Nueva Institucionalidad en Concesiones Mineras" <http://www.mch.cl/2015/04/27/plan-pro-inversion-gobierno-matiza-cambios-y-delinea-nueva-institucionalidad-en-concesiones-mineras $/>$.

77 Código Civil de Chile, artículo 583.

78 Constitución de la República de Chile, artículo 19 número 24.

79 Constitución de la República de Chile, artículo 20.

80 Véase Jana y Marín (1996).

81 Navarro Beltrán (2012), p. 628. 
Luego, la Corte Suprema chilena ha entendido que las entidades privadas tienen derechos de propiedad sobre intangibles. Aunque esta posición ha sido criticada por su impacto constitucional y en el sistema legal, ${ }^{82}$ es una práctica general el invocar los derechos de propiedad sobre las autorizaciones o contratos mediante el recurso de protección. ${ }^{83}$ Generalmente, estas demandas son exitosas. ${ }^{84}$

Reformar el marco regulatorio de las concesiones mineras, particularmente limitando la raíz de los derechos, calza perfectamente con la situación descrita. Si la reforma restringe los derechos ya otorgados, esto puede considerarse inconstitucional. Hay que tomar en cuenta la forma en que la Corte Suprema chilena ha entendido el derecho de propiedad sobre los intangibles; por lo que se espera que en el caso de las concesiones mineras la Corte argumentaría que el concesionario minero es dueño de los derechos otorgados por su concesión y, por lo mismo, que de limitarse o tomarse dichos derechos el Estado tendría que expropiarlos, indemnizando al concesionario. Lo anterior impide cualquier intento de restringir los derechos ya otorgados. ${ }^{85}$

\subsubsection{Inmutabilidad de los derechos adquiridos}

Algunos derechos no pueden ser alterados si fueron establecidos bajo una regulación particular. ${ }^{86}$ La inmutabilidad de los derechos adquiridos ha sido afirmada con base en el artículo 19 número 24 de la Constitución chilena. ${ }^{87}$ Esto responde al hecho de que Chile ha dado una interpretación amplia a los derechos de propiedad. En la práctica, la inmutabilidad significa que cualquier situación o derecho creado bajo un marco regulatorio particular no puede ser revisado o modificado por leyes posteriores. ${ }^{88}$

En el caso aquí considerado, la limitación de los derechos otorgados por una concesión minera sería considerada una violación de esta intangibilidad, establecida o construida por la Constitución chilena. Las consecuencias son las ya descritas: el Estado tiene que seguir un proceso de expropiación y, en cualquier caso, indemnizar a los concesionarios. Por tanto, esto imposibilita establecer limitaciones.

82 Ver Jana y Marín (1996).

83 Navarro Beltrán (2012), p. 627.

84 Navarro Beltrán (2012), p. 627.

85 Otra posibilidad que se analiza, pero está fuera de lo abordado en este artículo, es la alternativa y las consecuencias constitucionales que tendría crear un estatuto que haga aplicable el mandado constitucional de explorar o explotar la concesión minera, como se describió más arriba. En este caso, la diferencia es que ya existe una ley que obliga al concesionario a explorar o explotar la concesión, pero esta no es exigible. Así, la pregunta constitucional es si es constitucional forzar la ejecución de una norma que hace décadas no se aplica.

86 Sacco Aquino (2006).

87 Sacco Aguino (2006), p. 484.

88 Sacco Aguino (2006), p. 491. 


\subsubsection{Leyes orgánicas constitucionales}

Como se dijo, cualquier materia del marco regulatorio minero se regula en leyes orgánicas constitucionales. La Constitución chilena de 1980 incorporó las leyes orgánicas constitucionales en Chile. ${ }^{89}$ La existencia de leyes orgánicas constitucionales es controversial. ${ }^{90}$ Esto no suena familiar al lector de tradición common law ni quizás a casi todo lector de Derecho Civil.

Cuando un tema determinado es objeto de ley orgánica constitucional, los requisitos para su aprobación son diferentes. Las leyes orgánicas constitucionales requieren del 58\% de aprobación en cada Cámara del Congreso, además de un control obligatorio preventivo del Tribunal constitucional chileno. ${ }^{91}$

En el caso de las concesiones mineras, la duración, derechos y deberes que estas otorgan se somete al proceso de las leyes orgánicas constitucionales. ${ }^{92}$ Esto significa que aun si todos los problemas anteriores se resolvieran, para modificar el marco regulatorio actual no bastaría una ley simple. Se requiere el 58\% mencionado en cada Cámara y aprobación del Tribunal constitucional chileno.

En esta sección mostré algunos de los problemas a solucionar en caso de reformar el marco regulatorio actual, en caso de limitar de alguna forma los derechos ya otorgados por las concesiones mineras. El lector verá que el marco regulatorio actual no permite llevar a cabo dicha reforma, por lo que la solución al conflicto entre el uso de la tierra y el derecho minero debe buscarse en otros ámbitos. En la Parte IV de este artículo, describiré y presentaré una alternativa de solución para este conflicto.

\section{EXPOSICIÓN Y ANÁLISIS DEL TRATAMIENTO DE LOS GONFLICTOS EN TEXAS}

En la Parte IV, describo y analizo una doctrina que puede dar una solución alternativa al conflicto entre el titular de derechos mineros y el desarrollo de proyectos sobre la superficie. Esta doctrina se conoce como la acommodation doctrine y ha sido desarrollada en Texas. Antes de analizarla, justificaré por qué Texas es un caso interesante a observar. Luego, describiré el desarrollo de dicha doctrina en Texas.

\subsection{Por qué Texas}

En 2009, Texas concentraba más del 25\% de la generación de energía renovable eólica en el mercado eléctrico de Estados Unidos. ${ }^{93}$ El crecimiento en la capacidad de generar energía eléctrica en base al viento ha crecido exponencial-

89 Caldera Delgado (1984), p. 455.

90 Véase Verdugo (2012).

91 Constitución de la República de Chile, artículos 66 y 93.

92 Constitución de la República de Chile, artículo 19 número 24.

93 Duvivier y Wetsel (2009). 
mente. ${ }^{94}$ Texas es atractivo debido a las condiciones que tiene para crear parques eólicos. ${ }^{95}$ Los proyectos de energía solar desarrollados en Texas además requieren extensos terrenos. ${ }^{96}$

Los parques eólicos requieren grandes extensiones de tierra para desarrollarse. Esto, sumado a los requisitos de tierras para llevar a cabo estos parques, ha llamado la atención en cuanto al acceso y riesgos de llevar adelante este tipo de proyectos. Los desarrolladores de proyectos de energías renovables y los inversionistas ven que en Texas puede existir una posible interferencia de la industria del petróleo y el gas. ${ }^{97}$

La percepción del riesgo se basa en que en Texas coexisten diferentes derechos de propiedad en la misma área. Por un lado, está la propiedad sobre la superficie, y por el otro, la propiedad sobre los minerales ${ }^{98}$ de modo que existen derechos superficiales y otros derechos bajo la tierra. Para fines de este artículo no describiremos todo el sistema de propiedad de Texas, pero solo diremos que existe una división entre los derechos superficiales y los derechos bajo la tierra.

Dado esto, pueden surgir conflictos. En dichos conflictos, la propiedad sobre los minerales se considera dominante. ${ }^{99}$ En Texas existen razones relacionadas con las políticas para establecer la dominancia del mineral. ${ }^{100}$ Dicha dominancia significa que el propietario de los derechos mineros puede imponer servidumbres y este derecho puede ser indicado expresamente o de manera implícita. ${ }^{101}$

El crecimiento exponencial del sector de las energías renovables, la posibilidad de separar el derecho sobre las minas del de la superficie, la dominancia de los derechos mineros y el derecho a imponer servidumbres en la superficie, afectando así los derechos del propietario del terreno superficial o inquilino, convierten a Texas en un caso notablemente similar al chileno. De hecho, existen muchas diferencias, como la forma en la cual los derechos mineros se otorgan y la propiedad sobre los minerales, pero esas diferencias no impactan en el presente análisis.

En lo que sigue, describiré cómo este conflicto ha sido abordado en Texas.

\subsection{Cómo lidiar con los propietarios de derechos mineros en Texas para desa- rrollar proyectos de energía renovable}

Existen dos formas de lidiar con el acceso a la tierra del titular de derechos mineros sin riesgo de establecer una servidumbre. Por un lado, un desarrollador puede

\footnotetext{
94 Duvivier y Wetsel (2009), p. 9.

95 Duvivier y Wetsel (2009), p. 6.

96 Gardner, Sewell y Stahl (2010).

97 Diffen (2008), p. 241.

98 Gardner, Sewell y Stahl (2010).

99 Diffen (2008).

100 Diffen (2008).

101 Gardner, Sewell y Stahl (2010).
} 
llegar a un acuerdo con el propietario de derechos mineros. ${ }^{102}$ La forma del acuerdo puede variar, pero comúnmente serán renuncias a los derechos a la superficie o serán acuerdos de no interferencia. ${ }^{103}$

Sin embargo, el problema que nos convoca es el caso en que no es posible llegar a acuerdo con el dueño del terreno. En este contexto, la accomodation doctrine se vuelve relevante. ${ }^{104}$ En términos generales, la accomodation doctrine consiste en que si ya existe uso de la tierra superficial y el titular de los derechos mineros quiere hacer uso de la misma superficie para desarrollar su proyecto, el propietario del terreno superficial puede probar que existe una forma alternativa de efectuar ese uso sin afectar el derecho al uso del propietario superficial. ${ }^{105}$

Dado que el caso que me parece interesante es cuando no se llega a acuerdo, en la siguiente sección revisaré la historia y desarrollo de la accomodation doctrine.

\subsection{La accomodation doctrine}

La accomodation doctrine surgió como un mecanismo para dar alguna protección o compensación al dueño de la tierra superficial. ${ }^{106}$ Hafer y otros la han definido como "la doctrina del common law utilizada en Texas para restringir el derecho del dueño del mineral a usar la superficie en un predio donde el propietario superficial no es el propietario del mineral". ${ }^{107}$ El desarrollo de esta doctrina en Texas no es legislativo sino judicial. ${ }^{108}$ La primera manifestación fue en el caso Getty Oil Co. $v$ fones. ${ }^{109}$ En este caso, la Corte Suprema de Texas dictaminó que:

Donde ya existe un uso de la tierra por parte del dueño de la tierra superficial, el que se vería terminado o impedido, y según las prácticas de la industria existen formas alternativas para el inquilino y que permiten extraer el mineral, las reglas del uso razonable de la superficie pueden exigir al inquilino que opte por una de esas alternativas. ${ }^{110}$

De acuerdo con esta doctrina, el dueño de la tierra superficial puede impedir un determinado uso de los derechos mineros si existe una alternativa razonable para llevar a cabo el mismo proyecto. ${ }^{111}$ Esto hace que esta doctrina sea de ayuda para realizar instalaciones alternativas a la mina misma, puesto que esta no es removible.

\footnotetext{
102 Gardner, Sewell y Stahl (2010), p. 248.

103 Gardner, Sewell y Stahl (2010), p. 251.

104 Gardner, Sewell y Stahl (2010), p. 251.

105 Gardner, Sewell y Stahl (2010), p. 252.

106 Daintith (2014), pp. 43-44.

107 Hafer, Mathis y Simmons (2014), p. 81.

108 Miller (2003), p. 461.

109 Potter (2014), pp. 83-84.

110 Getty Oil Co v fones 470 S.W.2d 618, 622 (Tex, 1971).

111 Gardner, Sewell y Stahl (2010).
} 
El principal efecto de aplicar la accomodation doctrine es que el propietario del terreno superficial puede obligar a que el titular de derechos mineros lleve a cabo su proyecto en una forma alternativa y razonable, sin afectar el derecho al uso de la tierra del propietario del terreno superficial. ${ }^{112}$

La carga de la prueba de aplicar la accomodation doctrine recae en el dueño de la tierra superficial. ${ }^{113}$ Gardner y otros señalan que debe demostrarse tanto el deterioro o preclusión del uso actual como la existencia de una alternativa razonable para el titular de derechos mineros para concretar su proyecto. ${ }^{114}$ Hafer y otros desarrollaron un mayor entendimiento de estos requisitos señalando que hay cuatro elementos que debe probar el dueño de la tierra superficial. Primero, el uso actual de la tierra. Segundo, que dicho uso es el único medio razonable con que cuenta el propietario superficial para llevar a cabo su proyecto en su tierra. Tercero, que el uso propuesto por el propietario de derechos mineros afecta o acaba con el uso actual de la tierra que ejerce el propietario del terreno superficial. Finalmente, el propietario del terreno superficial debe probar la existencia de un método alternativo para desarrollar su proyecto, que no afectará el uso actual. ${ }^{115}$

Esta última construcción de la accomodation doctrine destaca que hasta en el caso en que las dos condiciones indicadas por Gardner y otros, se cumplen; igual existe un caso en el cual la accomodation doctrine no es y no debe ser aplicada. Me refiero al caso en que el dueño de la tierra superficial puede usar su tierra en alguna forma que no afecta el derecho al proyecto del titular de derechos mineros. ${ }^{116}$ La segunda condición de la versión de la accomodation doctrine de Hafer y otros, en que no puede aplicarse la doctrina, es si el propietario del terreno superficial puede utilizar la tierra en formas que no interfieren con el desarrollo del proyecto del titular de derechos mineros.

Sobre este último punto, deben mencionarse dos elementos: primero, esta característica implica una postura más consistente con la dominancia de la titularidad sobre los derechos mineros, ${ }^{117}$ aspecto que no es claro en la versión de Gardner y otros, el propietario del terreno superficial debe probar que el solo puede desarrollar su proyecto utilizando la tierra superficial como se está usando actualmente, por lo que, si este no puede probarlo, el titular de derechos mineros puede llevar a cabo su proyecto en la forma que él propone. La versión de Gardner y otros se centra solo en las alternativas razonables con que cuenta el operador del mineral. ${ }^{118}$

112 WeNZeL (1993).

113 Gardner, Sewell y Stahl (2010).

114 Gardner, Sewell y Stahl (2010).

115 Hafer, Mathis y Simmons (2014).

116 Hafer, Mathis y Simmons (2014), p. 61.

117 Hafer, Mathis y Simmons (2014).

118 Hafer, Mathis y Simmons (2014). 
Segundo, en el caso de los proyectos de energías renovables, es probable que se cumpla esta condición, puesto que, como se dijo anteriormente, los parques eólicos y los proyectos solares requieren de condiciones muy específicas respaldadas por diversos estudios técnicos y, de existir cambios mínimos en el diseño del proyecto, podría haber un impacto considerable en la capacidad de generación del proyecto. ${ }^{119}$

Por lo tanto, para mantener la noción de dominancia de la titularidad sobre derechos mineros de manera clara, es preferible seguir las condiciones de Hafer y otros. Sin embargo, y específicamente en el caso de las energías renovables, esta condición usualmente se cumple, pues un pequeño cambio en los requerimientos técnicos puede impactar significativamente la capacidad de generación.

Sin perjuicio de lo anterior, aún hay preguntas respecto de la accomodation doctrine. De hecho, debe determinarse qué es el uso actual de la superficie y qué se considera una alternativa razonable para el derecho del titular de derechos mineros.

Respecto de lo primero, la idea subyacente en Getty Oil Co. v Jones es que debe haber un uso concreto, más allá de una mera planificación. ${ }^{120}$ Sin embargo, esto es materia de interpretación, y su aplicación debe estudiarse caso a caso. Otro criterio a seguir, es que el uso actual no debe considerarse limitándolo a la fecha en que el permiso se otorga. ${ }^{121}$ La fecha o existencia de los permisos respectivos puede ser útil para determinar si solo hay planes o algo más, pero no puede ser el único criterio a seguir, porque no permite apreciar la existencia de proyectos reales.

Respecto de la razonabilidad de la alternativa para el dueño del mineral, un aspecto relevante es que la alternativa puede ser más cara que el plan original en la medida que, de todos modos, sea razonable. ${ }^{122}$ Además, las prácticas y usos de la industria deben servir de guía para medir la razonabilidad de la alternativa. ${ }^{123}$ Luego, la razonabilidad de la alternativa se relaciona con las prácticas generales de una industria específica más que con sus costos.

Una pregunta adicional es si la accomodation doctrine puede aplicarse a los minerales duros. En este sentido, Wenzel expresa que no hay razón para restringir el uso de la accomodation doctrine solo a la industria del petróleo o el gas y, en consecuencia, puede además aplicarse a los minerales duros. ${ }^{124}$

Como queda en evidencia, la Corte Suprema de Texas desarrolló la accomodation doctrine para abordar un problema similar al que hoy enfrenta Chile. Esta doctrina refleja una relación más equitativa entre el desarrollo de proyectos mineros y de

119 Véase Duvivier y Wetsel (2009).

120 Hafer, Mathis y Simmons (2014).

121 Gardner, Sewell y Stahl (2010).

122 WeNZEL (1993).

123 Alspach (2002).

124 Wenzel (1993). 
tierra superficial. ${ }^{125}$ Reconoce la relevancia del dominio de los derechos mineros pero brinda la opción de evaluar y sopesar el desarrollo de un proyecto en la superficie y principalmente la coexistencia entre los intereses de los propietarios de derechos mineros y de la tierra superficial. ${ }^{126}$ En la parte siguiente se analizará cómo adoptar y adaptar la accomodation doctrine en el sistema jurídico chileno.

\section{CÓMO PUEDE INCORPORARSE LA $A C C O M O D A T I O N$ DOCTRINE AL SISTEMA JURÍDICO GHILENO Y SUS EFEGTOS}

\subsection{Beneficios de la accomodation doctrine en el contexto chileno}

Como se indicó, la reforma del marco regulatorio actual de las concesiones mineras en Chile parece ser el paso que debe darse para mejorar el resultado del sistema y para enfrentar los problemas de las energías renovables. Sin embargo, como se demostró, es muy complejo enmendar el marco regulatorio sin caer en la discusión de la constitucionalidad de dicha reforma. La alternativa propuesta en este artículo es adoptar, y adaptar, la accomodation doctrine al sistema jurídico chileno.

Esta doctrina refleja una relación más equitativa entre el uso de la tierra y las actividades mineras, ${ }^{127}$ manteniendo la dominancia de la titularidad sobre los derechos mineros. Lo anterior es de todos modos consistente con el sistema actual establecido en la Constitución chilena. Además, esta propuesta Evita el problema constitucional que una reforma con efecto retroactivo tendría.

Además, la accomodation doctrine aborda el conflicto de la especulación en Chile. Dado que el propietario del suelo superficial obliga al titular de derechos mineros a desarrollar su proyecto sin afectar su tierra, en caso de cumplirse ciertas condiciones, el titular del derecho minero estaría obligado a mostrar un plan de desarrollo original de un proyecto minero. Por definición, un "especulador" no tiene plan.

\subsection{Cómo adoptar la accomodation doctrine en el sistema jurídico chileno}

En esta sección, describiré los aspectos principales a considerar al adoptar la accomodation doctrine en Chile. Puesto que es una propuesta, cualquiera de estos puntos requerirá de mayor discusión.

Primero, la accomodation doctrine no puede ser solo una construcción judicial. En Chile, las sentencias no son vinculantes para decisiones posteriores. ${ }^{128}$ Por tanto, para ser efectiva, se requiere además de un apoyo legislativo. En este sentido, es importante mencionar que sería necesaria una ley orgánica constitucional. Respecto de esto, la accomodation doctrine debe ser incorporada como una defensa en el proceso de

\footnotetext{
125 WeNZEL (1993), p. 630.

126 WeNZEL (1993).

127 WeNZEL (1993).

128 Código Civil de Chile, artículo 3.
} 
constituir servidumbres y en el orden judicial, para suspender los procesos de obras. Esto significa que, para adoptar sistemáticamente esta posibilidad, se requiere aprobar una ley y cumplir con un cierto quórum. Además, el titular de derechos mineros deberá acompañar a la demanda en ambos casos el plan de trabajo para que sea evaluado por el juez y por el propietario de la tierra superficial. Este debiera ser un requisito de admisibilidad.

Segundo, la accomodation doctrine podría ser una defensa no solamente para el dueño sino también para el inquilino de las tierras. Normalmente, los desarrolladores de proyectos de energías renovables no son los dueños de las tierras en las cuales se llevan a cabo dichos proyectos. Ellos tienen un acuerdo con el dueño de la tierra para poder usarla. Dichos acuerdos podrían ser suficientes para oponerse a la defensa de la accomodation doctrine.

Tercero, el "uso actual" podría ser probado o determinado en relación con el "inicio de las obras" establecido en la legislación actual. ${ }^{129}$ De acuerdo con esta legislación y las reglas de interpretación de dicha regulación, ${ }^{130}$ el titular de un permiso ambiental puede probar el inicio de las obras si muestra el desarrollo de cualquier acción o trabajo sistemático, ininterrumpido y permanente de una etapa de construcción del proyecto.

Finalmente, la razonabilidad de las alternativas puede seguir el mismo principio desarrollado en la accommodation doctrine de Texas. Esta es la práctica general de la industria específica.

\section{GONGLUSIÓN}

En este artículo, describí la estructura de las concesiones mineras en Chile, mostrando los problemas que genera para el desarrollo de proyectos de energías renovables. Luego, analicé las cuestiones constitucionales que surgen si se intentara modificar el marco regulatorio actual. Además, describí cómo Texas abordó el mismo conflicto creando y desarrollando la accomodation doctrine. Luego, entregué ideas sobre cómo esta doctrina podría incorporarse en Chile y cómo podrían solucionarse los problemas entre el uso de la tierra para proyectos de energías renovables y los derechos de los concesionarios mineros. Con base en lo anterior, concluí que la $a c^{-}$ comodation doctrine es útil para generar una relación más equitativa entre el uso de la tierra superficial y los derechos mineros y su incorporación en el sistema legal chileno sería beneficioso para el desarrollo de proyectos de energías renovables, evitando los problemas que hoy tiene la industria en relación con las concesiones mineras.

129 Ley de Bases Generales del Medio Ambiente, artículo 25 ter.

130 Servicio de Evaluación Ambiental, “Ord. N 142034/2014. Imparte instrucciones en relación al artículo 25 ter de la Ley $\mathrm{N}^{\circ}$ 19.300, al artículo 73 del reglamento del sistema de evaluación de impacto ambiental y al artículo 4 transitorio del referido reglamento". 


\section{BIBLIOGRAFÍA CITADA}

Alspach, Christopher M. (2002): "Surface Use by the Mineral Owner: How Much Accommodation Is Required Under Current Oil \& Gas Law?", Oklahoma Law Review, Vol. 55, pp. 89-118.

Agurto, Renato et al. (2003): "Impacto Macroeconómico del Retraso de las Inversiones de Generación Eléctrica en Chile". Universidad Alberto Hurtado - Synex, May 2013.

Bambach, Juan Paulo (2003): "Conflictos entre los concesionarios mineros con los propietarios del suelo", Revista de Derecho Administrativo Económico, Vol. 1, pp. 65-74.

Caldera Delgado, Hugo (1984): “Ley Orgánica Constitucional y Potestad Reglamentaria", Revista Chilena de Derecho, Vol. 11, pp. 455 y ss.

DAINTITH, Terrence (2014): "The Common Law of Underground Energy Resources in the United States", en Zillman Donald N. et al. (eds.), The Law of Energy Underground. Understanding New Developments in Subsurface, Production, Transmission, and Storage (Oxford University Press).

Diffen, Becky H. (2008): "Note \& Comment. Energy From Above and Below. Who Wins When a Wind Farm and Oil \& Gas Operation Conflict?", Texas fournal of Oil, Gas and Energy Law, Vol. 3, pp. 240 y ss.

Dossi Osorio, Giovanna (2016). Las acciones posesorias en la minería (Círculo Legal Editores).

Duvivier, K.K. y Roderick, E. Wetsel (2009). "Jousting at Windmills: When Wind Power Development Collides With Oil, Gas and Mineral Development", Rocky Mountain Mineral Law Institute, Vol. 55, pp. 9 y ss.

Gardner, Alison, Sewell, David y Stahl, Brent (2010): “Mineral Issues' Impact on Solar Energy Development in Texas", Texas fournal of Oil, Gas and Energy Law, Vol. 6, pp. 241 y ss.

Hafer, Douglas R., Mathis Daniel B. y Simmons, Logan W. (2010): "A Practical Guide to Operator/Surface-Owner Disputes and the Current State of the Accommodation Doctrine", Texas Wesleyan Law Review, Vol. 17, pp. 47 y ss.

Huerta Molina, José Miguel y Rodríguez Diez, Javier (2012): "Suspensión Interdictal de Obras Nuevas. Desde la "Operis Novi Nuntiato" Hasta el Proyecto de Código Procesal Civil", Revista de Derecho de la Universidad Católica de Valparaíso, Vol. 38, pp. 342 y ss.

Insunza Corvalán, Ximena (2015): Análisis crítico del estatuto jurídico de la minería como barrera para el desarrollo de la energía solar en Chile (Universidad de Chile y Solar Energy Research Center). 
Jana, Andrés y Marín, Juan Carlos (1996): Recurso de protección y contratos (Editorial Jurídica de Chile).

Jones, Kendor P., Welborn, John F. y Russell, Chelsey J. (2013): "Split estates and surface access issues", Landman's Legal Handbook: A Practical Guide to Mineral Leasing (5 ${ }^{\mathrm{a}}$ ed.), pp. 181-190.

Lira Ovalle, Samuel (1998): Curso de Derecho de Minería (Editorial Jurídica de Chile, 3rd ed.)

Miller, A.M. (2003): “Comment. A Journey through Mineral Estate Dominance, the Accommodation Doctrine, and Beyond: Why Texas Is Ready to Take the Next Step with a Surface Damage Act”, Houston Law Review, Vol. 40, pp. 461 y ss.

Moraga Sariego, Pilar (2012): "Las Razones de la Conflictividad del Sector Eléctrico: El Caso de la Consulta Indígena", Anuario de Derecho Público, Vol. 1, pp. 376-391.

Navarro Beltrán, Enrique (2012): “35 Años Del Recurso de Protección. Notas sobre su Alcance y Regulación Normativa”, Estudios Constitucionales, Vol. 10, pp. 617 y ss.

NovoA, Laura y Bambach, Juan Pablo (2017): “Uso inadecuado del Régimen Legal Minero", Revista de Derecho Administrativo Económico, Vol. 1, pp. 49-56.

Obando Gamino, Iván Mauricio (2010): "La servidumbre legal minera de ocupación de predios superficiales por canales y cañerías de aguas. Notas sobre un conflicto normativo", Revista de Derecho de la Pontificia Universidad Católica de Valparaíso, Vol. 25, pp. 269-303.

Ossa Bulnes, Juan Luis (1999): Derecho de Minería (Editorial Jurídica de Chile, 3rd ed.)

Potter, Gourtney R. (2014): “The Accommodation Doctrine Revisited: Implications in Law and in Policy", Saint Mary's Law fournal, Vol. 46, pp. 75 y ss.

Sacco Aquino, Sabina (2006): "La Constitución de 1980 como Fundamento y Origen de una Teoría Constitucional de la Irretroactividad", Revista Chilena de Derecho, Vol. 33, pp. 479-508.

Verdugo, Sergio (2012): "Las Justificaciones de la Regla de Quórum SupraMayoritaria de las Leyes Orgánicas Constitucionales", Revista de Derecho de la Universidad Católica de Valparaíso, Vol. 34, pp. 395 y ss.

Vergara Blanco, Alejandro (1988): "Esquema del Procedimiento Concesional Minero", Revista de Derecho de la Universidad Católica de Valparaíso, Vol. 12, pp. 245 y ss.

Vergara Blanco, Alejandro (1989): "Sobre los Derechos Mineros en Chile", Revista Chilena de Derecho, Vol. 16, pp. 43 y ss.

Vergara Blanco, Alejandro (2003): “Crónica de la Ley Orgánica Constitucional sobre Concesiones Mineras de 1982 y de su Real Impacto en la Doctrina y la Jurisprudencia", Revista de Derecho Administrativo Económico, Vol. 5, pp. 23 y ss. 
Vergara Blanco, Alejandro (2012): "Regulación del Procedimiento Concesional Eléctrico. Diagnóstico de Problemas", Actas de Derecho de Energía, Vol. 1, pp. 401 y ss.

Vergara Blanco, Alejandro (2014): "La Contemporánea Regulación de la Minería en Chile. Crítica a las Teorías Tradicionales del Dominio Estatal de las Minas", Derecho Administrativo. Revista de Jurisprudencia, Legislación y Práctica, Vol. 93, pp. 633 y ss.

Wenzel, Michelle Andrea (1993): "The Model Surface Act Use and Mineral Development Accommodation Act: Easy Easements for Mining Interests", The American University Law Review, Vol. 42, pp. 607 y ss.

Zillman, Donald N. et al. (eds.) (2014): The Law of Energy Underground. Understanding New Developments in Subsurface, Production, Transmission and Storage (Oxford University Press).

ZúÑIga Urbina, Francisco (2005). "Constitución y dominio público: Dominio público de minas y aguas terrestres", Revista Ius et Praxis, Vol. 11, No 2, pp. 65-101. 